\title{
AS ORGANIZAÇÕES SOLIDÁRIAS NO MUNICÍPIO DE CASCAVEL/PR, E A IMPORTÂNCIA DA EDUCAÇÃO PARA O DESENVOLVIMENTO TERRITORIAL JUSTO E SUSTENTÁVEL
}

\author{
Jonatas dos Santos BARRETO 1 \\ Roberto Antonio DEITOS ${ }^{2}$ \\ https://orcid.org/0000-0001-9150-6354 \\ Irene Carniatto de OLIVEIRA ${ }^{34}$ \\ https://orcid.org/0000-0003-1140-6260
}

\begin{abstract}
Resumo: O presente trabalho tem por objetivo analisar os empreendimentos econômicos solidários no município de Cascavel/PR, que buscam como alternativa de sobrevivência a coletividade, em meio ao sistema exploratório do mundo do trabalho, que projetou a reestruturação das Políticas Sociais, contribuindo para a territorialização e efetivação da sustentabilidade. O estudo é norteado por meio de análise e observação do processo de formação dos beneficiários, capacitados através do projeto CFES - Centro de Formação de Economia solidária no estado do Paraná, especificamente, na Cidade de Cascavel, que foi selecionada como núcleo potencial. Desta forma, diagnosticar-se-á quais as contribuições deste processo de formação e as principais dificuldades para a busca da autogestão dos empreendimentos, que passaram por este processo de formação, tendo como base a organização dos catadores de materiais recicláveis locais.
\end{abstract}

Palavras Chave: Trabalho. Educação Ambiental. Empreendimentos Solidários. Sustentabilidade.

Abstract: The objective of this article is to analyze economic solidarity projects in the municipality of Cascavel / PR, which seek as an alternative of survival and collectivity, in the middle of the exploratory system of the world of work, which projected the restructuring of Social Policies, contributing to territorialisation And effectiveness of sustainability. The study will be guided by analysis and observation of the process of training beneficiaries, trained through the project CFES - Solidary Economy Training Center in the state of Paraná, specifically in the city of Cascavel, which was selected as a potential nucleus. In this way, it is possible to diagnose the contributions of this training process and the main difficulties in the search for self-management of the enterprises that have undergone this training process, based on the organization of local waste pickers.

Key Words: Work. Environmental Education. Solidary Enterprises. Sustainability.

1 Assistente Social, Mestre em Educação pela UNIOESTE - Programa de Pós-graduação em Educação Nível de mestrado/PPGE. Cascavel, PR, E-mail: jonatasbarreto@live.com.

2 Prof. Dr. do Programa de Pós-graduação em Educação Nível de Mestrado e Doutorado/PPGE, da Universidade Estadual do Oeste do Paraná, Cascavel, PR, rdeitos@uol.com.br.

3 Prof ${ }^{a}$ Dr ${ }^{a}$ do Doutorado em Desenvolvimento Rural Sustentável - UNIOESTE - Campus Rondon Coordenadora do CEPED - Centro de Ensino, Pesquisa e Extensão em Proteção e Desastres UNIOESTE. E Coordenadora do LABHEA - Laboratório de Estudos em Bacia Hidrográfica e Educação Ambiental, da Universidade Estadual do Oeste do Paraná, Cascavel, PR, irenecarniatto@gmail.com.

4 Coordenadora da Rede Internacional de Pesquisa em Desenvolvimento Resiliente ao Clima RIPEDRC - Rede Resiliência Climática. 


\section{INTRODUÇÃO}

A proposta consistiu em analisar as políticas sociais de inclusão produtiva, identificando as ações de geração de trabalho e renda, ditas como "políticas públicas" para inclusão social das pessoas de baixa renda, com rendimentos providentes do trabalho "informal" e fazem parte dos empreendimentos econômicos solidários. A lógica do movimento vem em oposição ao sistema capitalista. Abordamos a problemática da exclusão social, de um mercado formal que selecionada sua mão de obra, sobre as bases da exploração da mais valia. E o que fazer com o excedente? A aquele que para os olhos do capital não é mais produtivo?

Gadotti, em seus estudos, faz referência em sua obra, "Economia Solidária Volume 1", que o conceito de economia Solidária aparece no Brasil em meados do ano de 1993.

O autor chileno, Luiz Razeto indaga como:

Uma formulação teórica de nível científico, elaborada a partir e para dar conta de conjuntos significativos de experiências econômicas que compartilham alguns traços constitutivos e essenciais de solidariedade, mutualismo, cooperação e autogestão comunitária, que definem uma racionalidade especial, diferente de outras racionalidades econômicas (RAZETO, 1993, p.40).

O movimento de economia solidária, que surge para atender a demanda dos trabalhadores à exclusão e exploração do mundo do trabalho, traz consigo o resgate do processo histórico, de lutas dos trabalhadores do início do século XIX.

5 As Políticas Sociais, ditas "públicas", nascem dos direitos Sociais Fundamentais, garantidos, constitucionalmente, a todos, e se enfatiza, desta forma, uma atuação positiva por parte do Estado. Através das políticas públicas, que implementam programas sociais, muitas vezes, atrelados aos objetivos de potencializar esses direitos, no intuito da realização da cidadania plena.

5 Trabalho "informal" se remete ao subemprego, ao trabalho não regimentado. Ricardo Antunes, em sua obra, Adeus ao Trabalho? Salienta, "paralelamente a essa tendência, há outra também extremamente significativa, dada pela sub proletarização do trabalho, presente nas for

mas de trabalho precário, parcial, temporário, subcontratado, 'terceirizado', vinculados à 'economia informal'”.
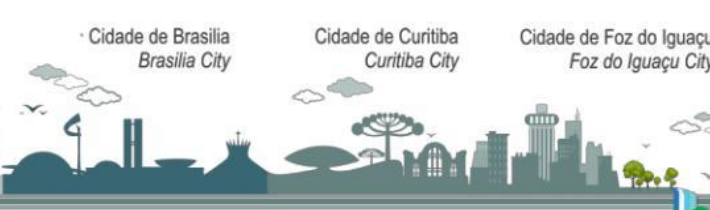


\section{International Juurnal of Environmental}

\section{Resilience Research and Science (IJERRS)}

Revista Internacional Resiliência Ambiental Pesquisa e Ciência Saciedade 5.0 Resiliência Ambiental

Juntando forças, desde meados de 1990, vem se fortalecendo o movimento de economia solidária no Brasil, não muito diferente do restante do país, essa prática se ramifica e desenvolve várias ações na região oeste do estado do Paraná. Ainda, por se tratar de uma política de assistência social, delimita o acesso, beneficiando o recorte do público dos programas federais de transferência de renda. A economia solidária é um jeito diferente de produzir, vender, comprar e trocar, sem exploração da mão de obra, garantido o cuidado com o meio ambiente para as próximas gerações. Esta prática vem se apresentando, nos últimos anos, como uma alternativa inovadora de geração de trabalho e renda e uma resposta ao fator da inclusão social. Esta nova economia, compreende uma diversidade de práticas econômicas, sendo: cooperativas, associações, empresas autogestionadas, redes de cooperação, entre outras. Os empreendimentos seguem nos mais variados ramos de atividades, de prestação de serviço, de produção de bens, finanças solidárias, comércio justo e consumo solidário.

Considerando essas características, a economia solidária aponta para uma nova lógica de desenvolvimento sustentável com geração de trabalho e distribuição de renda, mediante um crescimento econômico com proteção dos ecossistemas. Seus resultados econômicos, políticos e culturais são compartilhados pelos participantes, sem distinção de gênero, idade e raça. Isso implica na reversão da lógica capitalista ao se opor à exploração do trabalho e dos recursos naturais, considerando o ser humano na sua integralidade como sujeito e finalidade da atividade econômica.

No ano de 2002, acontece a 1ㄹ Plenária Nacional de Economia solidária, em São Paulo, que direciona para o ano seguinte, a criação da Secretaria Nacional de Economia solidária no âmbito do Ministério do Trabalho e Emprego, e, também, a realização da Terceira Plenária Nacional de Economia solidária, criando o FBES Fórum Brasileiro de Economia solidária.

Para deliberar as ações, o Ministério do Trabalho e Emprego, com o foco na Economia solidária a SENAES - Secretária Nacional de Economia solidária, 


\section{International Juurnal of Environmental}

\section{Resilience Research and Sciente (IJERRS)}

Revista Internacional Resiliência Ambiental Pesquisa e Ciência Saciedade 5.0 Resiliência Ambiental

protagonizou um importante papel frente aos avanços do movimento de economia solidária. Várias ações, cronologicamente, foram realizadas, como, por exemplo, em 2003, a criação da rede de gestores governamentais de políticas públicas de economia solidária, mobilização de articulação desde 1980; em 2004, foi realizado o 1ํ. Encontro Nacional de Empreendimentos Econômicos Solidários, que teve a participação de mil empreendimentos; no ano 2006, acontece à $1^{\text {a }}$ Conferência Nacional de Economia solidária, que mobilizou mais de quinze mil pessoas em suas etapas preparatórias (estaduais e microrregionais) e 1.200 pessoas na etapa nacional, com o lema: "O direito e as formas de organização econômica baseada no trabalho associado, na propriedade coletiva, na cooperação e na autogestão, reafirmando a Economia solidária como estratégia e política de desenvolvimento"; em 2008, foi realizado a IV Plenária Nacional de Economia solidária; e, por último, em 2010, realizou-se II Conferência Nacional de Economia solidária (CONAES), com o seguinte lema: "Pelo Direito de Produzir e Viver em Cooperação de Maneira Sustentável".

Já no estado do Paraná, tornou-se Política de Governo a partir de 2003, com o governo Roberto Requião, o qual iniciou projetos voltados para esta área. No ano 2008, inicia-se o programa Brasil Local, que contava com 510 Agentes, presentes nos 26 estados e no Distrito Federal, programa este, que tinha como objetivo mapear os empreendimentos solidários e suas principais dificuldades, conforme reportagem de Alexandre Takazawa, denominada "Artesãos da região participam de projeto Brasil Local", publicada em 13 de março de 2008, no site assisnoticias.com.

Já a economia solidária local, iniciou suas ações a partir da realização da $1^{\text {a }}$ Conferência Regional de Economia solidária do Oeste do Paraná, realizada em 26 de março de 2010, no anfiteatro da Universidade Estadual do Oeste do Paraná, no município de Cascavel. Este evento contou com a participação de feirantes da agricultura familiar e empreendimentos coletivos de artesões, que de uma maneira acanhada apresentaram seus produtos mesmo ainda não se percebendo no contexto 


\section{International Journal of Environmental Resilience Research and Sciente (IJERRS)}

Revista Internacional Resiliência Ambiental Pesquisa e Ciência Saciedade 5.0 Resiliência Ambiental

da economia solidária. A partir do sucesso da conferência, que atingiu um público de aproximadamente 600 pessoas, que propuseram a organização do movimento, por meio das capacitações, indicativo também proposto na I Conferência, tendo em vista seria de extrema importância à troca de informações e aprimoramento dos empreendedores solidários.

A economia solidária, vista como movimento, busca alternativas, frente ao sistema do capitalismo se fortalece nas bases da educação popular, construindo uma sistematização importante, que contribui, significativamente, para alavancar as organizações solidárias. Este fortalecimento foi possível por meio das formações do Projeto Nacional, CFES - Centro de Formação e Assessoria Técnica em Economia solidária, que busca protagonizar a emancipação da autogestão dos autores deste movimento, ou seja, por meio do empoderamento, ou pelo processo de multiplicação, dos apoiadores, técnicos e gestores de políticas sociais.

\section{METODOLOGIA}

A coleta de dados e informações foi feita de forma direta, através de acesso à documentação, como relatórios de capacitações, relatórios de entidades parceiras, atas e estatutos dos empreendimentos, observação das metas e etapas de formação, bem como os relatórios de sistematização do Projeto CFES - Centro de Formação em Economia solidária, referente à execução do Projeto no ano de 2009 a 2015. Além de outras fontes, pois essas ações estão entrelaçadas entre si, perfazendo uma ligação com as demais políticas socais.

Os resultados alcançados pelo estudo não devem ser mensurados apenas com números e valores, mas sim transcrever as conquistas sociais do trabalho cotidiano de resgate da dignidade humana. É um resultado que não pode ser avaliado de forma quantitativa e qualitativa, tendo como base o desenvolvimento e potencialidade locar dos movimentos sociais, empreendimentos e entidades sociais fomentadoras. 


\section{International Journal of Environmental Resilience Research and Sciente (IJERRS)}

Revista Internacional Resiliência Ambiental Pesquisa e Ciência Saciedade 5.0 Resiliência Ambiental

\section{RESULTADOS E DISCUSSÃO}

A construção do termo economia solidária nos remete a um mundo de possibilidades, contendo em sua essência a direta correlação entre uma forma inovadora de produção, para ter uma vida digna sem que com isso ponha em xeque questões fundamentais, como a preservação do meio ambiente e as relações humanas entre os agentes produtivos.

O processo econômico solidário aponta para uma nova lógica de desenvolvimento social e técnico, capaz de apoiar uma nova forma de pensar a dinâmica social e produtiva, rompendo com a busca individualista, característica de uma sociedade capitalista onde poucos são os beneficiários e muitos são os sacrificados.

A economia solidária vem se apresentando como uma forte vertente de solução. Nos últimos anos, há uma necessidade que se apresenta cada vez mais latente, relacionada a uma nova alternativa na geração de trabalho e renda que alcance aquelas pessoas em situação de vulnerabilidade e risco social, configura-se, assim, como uma resposta positiva a favor da necessidade de inclusão social do Plano Brasil Sem Miséria.

Os empreendimentos solidários são uma alternativa ao mundo de desemprego crescente, em que a grande maioria dos trabalhadores não controla nem participa da gestão dos meios e recursos para produzir riquezas e em que um número sempre maior de trabalhadores e famílias perdem o acesso à remuneração e fica excluído do mercado capitalista. Os empreendimentos solidários buscam reverter a lógica da espiral capitalista, em que o número dos que têm acesso à riqueza material é cada vez mais reduzido, enquanto aumenta, rapidamente, o número dos que só conseguem compartilhar a pobreza e a desesperança, necessitando de benefícios públicos para atender às suas necessidades mais elementares. 


\section{International Journal of Envirnnmental}

\section{Resilience Research and Science (IJERRS)}

Revista Internacional Resiliência Ambiental Pesquisa e Ciência Saciedade 5.0 Resiliência Ambiental

Os empreendimentos solidários afirmam a emergência de novo ator social, configurando também a nova forma de trabalhadores e consumidores conscientes e solidários, como sujeito histórico para a superação sistêmica dessa situação. Regido pelos princípios básicos, com vertente direto do cooperativismo.

Para combinar o processo integral de qualificação social e profissional, o Movimento de Economia Solidária coloca a metodologia de formação/educação popular em Economia solidária como evidência, como oportunidades de elevação de escolaridade e com outras iniciativas de formação da política cidadã.

Nas palavras de Ribeiro:

Discutir os temas da cidadania e do ambiente remete a questões de caráter ético político. Mas também a esferas do mundo material. Trata-se de permitir que a livre expressão, uma das maneiras de interpretar e praticar a cidadania possam ser exercidos sobre a base material que sustenta a vida humana. Diante de um cenário de escassez de recursos naturais, é preciso muita capacidade de organização política para conciliar interesses diversos. O desafio consiste na elaboração de uma ética ambiental que permita a livre expressão também no campo da reprodução material da vida (RIBEIRO, 2003, p. 399).

Como exemplo, o Movimento Nacional dos Catadores que luta pelo reconhecimento profissional da categoria, sabendo que muitas vezes os catadores não reconhecem a catação como profissão. Aliado a esse processo, desenvolve-se

socialmente o estigma do sujeito catador, pode-se verificar essa situação, quando se realizam cadastros, pois omitem-se as informações, declarando-se outras profissões exercidas anteriores, ou relatam que estão vivendo de "bico".

Podemos citar a COOTACAR, como empreendimento econômico solidário, em sua plenitude, que desenvolve suas ações pautadas nos princípios básicos do cooperativismo, com foco a Economia Solidária e na Educação Ambiental. Que desenvolve importante trabalho social e comunitário, na área de resíduos sólidos urbanos, realizando a coleta seletiva solidaria, processando os materiais coletados e gerando renda direta para mais de setenta famílias de catadores.

Resultado importantíssimo, alçado através de inúmeros parceiros, em especial as Universidades. Um dos destaques, foi o curso de Gestão em Empreendimentos 


\section{International Journal of Environmental}

\section{Resilience Research and Science (IJERRS)}

Revista Internacional Resiliência Ambiental Pesquisa e Ciência Saciedade 5.0 Resiliência Ambiental

Econômicos Solidários, executado em parceria com a Secretária Estadual do Trabalho, com recurso do Fundo de Amparo ao Trabalho (FAT), o Projeto de Capacitação Cataforte, executado na em parceria com Instituto Lixo e Cidadania e Itaipu Binacional e Caixa Econômica Federal, qualificando os cooperados e elaborando o Plano Social de Negócio.

A SENAES lança diversos editais para execução de capacitações em todas as regiões do país. Neste contexto em meados de 2005 a 2007, respectivamente, são ofertadas oficinas de capacitação/educação, através do Fórum Nacional de Economia solidária (FBES), com objetivo de identificar as experiências, e que estas dialogassem entre seus atores, construindo a base orientadora da Economia solidária.

Em 2008, lança-se o edital para execução do projeto CFES - Centro de Formação em Economia solidária, que capacitou o coletivo de educadores, os quais ficaram com a missão de replicar os conhecimentos à base. Este projeto foi desenvolvido no período de 2009 a 2012. Logo em seguida, inicia-se o CFES II, que tem como objetivo a capacitação dos alunos e ex-alunos do PRONATEC, agentes de desenvolvimento de políticas públicas, os gestores públicos, os agentes de políticas públicas, os empreendedores solidários e demais beneficiários dos projetos e programas cofinanciados pela SENAES. Este projeto está em andamento e, no estado do Paraná, está sendo executado em dois territórios estratégicos, sendo: Mesorregião metropolitana de Curitiba, tendo como cidade sede a Capital e Mesorregião do Oeste do Paraná, tendo a cidade sede Cascavel. A escolha foi realizada através do comitê gestor do Projeto CFES, que identificou as regiões como potencial para alavancar o Movimento de Economia solidária, tendo em vista os processos históricos vivenciados.

Para execução geral do Projeto na região sul do País, foi selecionada a entidade a CAMP - Centro de Assessoria Multiprofissional, localizada em Porto Alegre, no estado do Rio Grande do Sul, onde está centralizado a sede geral do Projeto CFES. A entidade tem uma longa caminhada na Economia solidária, organização não 


\section{International Juurnal of Environmental Resilience Research and Sciente (IJERRS)}

Revista Internacional Resiliência Ambiental Pesquisa e Ciência Saciedade 5.0 Resiliência Ambiental

governamental, brasileira, fundada em 1983 por jovens estudantes, religiosos ligados à teologia da libertação e sindicalistas urbanos e rurais.

No Paraná, a entidade credenciada para execução, foi o Instituto Nhandecy, que é uma organização sem fins lucrativos, que impulsiona projetos para o bem viver coletivo, coordenando, divulgando e propiciando que o público em geral tenha acesso permanente às atividades e às metodologias participativas de alta qualidade, reconhecidas nacional e internacionalmente.

Para execução das ações formativas no estado, o Instituto Nhandecy, juntamente aos demais apoiadores, programou-se para a execução e cumprimento das metas estabelecidas pela conjuntura do Projeto Nacional. O projeto trouxe como desafio uma pluralidade de atores sociais, que formariam o leque de metas e objetivos a serem alcançados.

As capacitações foram divididas entre dez oficinas territoriais, com carga horário de quatro horas cada uma, e com públicos específicos para cada oficina; oito oficinas territoriais, de oito horas cada uma; cinco oficinas estaduais, de 20 horas cada uma, com as seguintes temáticas: a) Finanças solidárias (fundos rotativos, bancos comunitários, cooperativas de crédito), b) Comercialização, certificação, comércio justo e solidário, c) EES e suas redes e cadeias de produção e Comercialização; d) Processos de desenvolvimento territorial incluindo o etnodesenvolvimento; e) Organização de segmentos populacionais e profissionais específicos.

Um curso estadual de cento e sessenta horas para o público prioritário, sendo: os beneficiários do Plano Brasil Sem Miséria; Agentes de Desenvolvimento que atuam nas ações integradas de Economia solidária, na promoção de políticas de superação da extrema pobreza do governo federal; agentes de Desenvolvimento que prestam Assessoria Técnica, voltadas para oficinas específicas; educadores dos programas EJA, PRONATEC; Mulheres Mil e Rede Certific, e outros programas de educação do governo federal. 


\section{International Journal of Environmental Resilience Research and Sciente (IJERRS)}

Revista Internacional Resiliência Ambiental Pesquisa e Ciência Saciedade 5.0 Resiliência Ambiental

Um curso estadual de 60 horas, para servidores, gestores e agentes públicos, em especial, àqueles que atuam diretamente na promoção de políticas de superação da extrema pobreza do Governo Federal; lideranças de movimentos sociais, uniões e fóruns de economia solidária; equipes multidisciplinares de bases de serviço de assessoria aos empreendimentos econômicos solidários, formadores de agentes de desenvolvimento e assessores técnicos; equipes de coordenação técnica de projetos executados em parceria com a SENAES.

\section{CONSIDERAÇÕES FINAIS}

Analisando o processo de formação, percebemos que o empoderamento por parte dos empreendimentos participantes, a rica troca de experiência no processo de formação, tanto no Projeto do Centro de Formação em Economia Solidária, bem como nas formações em locais, ofertadas por entidades de assessoramento, resulta no processo de trocas de experiência.

Porém, a analise não pode ser superficial, tendo em vista que os "atores" desta economia, muitas vezes, estão em busca de resultados concretos, como a própria geração de receita para a sobrevivência. Observa-se que as iniciativas que apresentam resultados positivos, tiveram cofinanciamento do poder público, entidades de apoio, ou sistemas de incubação através das universidades.

A busca pela autogestão está suprimida em meio a um cenário gigantesco, pois está acima de uma simples gestão compartilhada e independente. São fatores, técnicas, recursos humanos e financeiros, gestões e compartilhamento das informações, que fazem com que de fato os empreendimentos possam ser denominados "auto gestores".

O movimento de economia solidária, bem como os demais movimentos sociais vem se enfraquecendo, situação vivenciada pelo modelo hegemônico capitalista, 


\section{International Journal of Environmental}

\section{Resilience Research and Science (IJERRS)}

Revista Internacional Resiliência Ambiental Pesquisa e Ciência Saciedade 5.0 Resiliência Ambiental

protagonizando o adormecimento da massa pela luta da manutenção dos direitos sociais conquistados.

Mesmo com o processo de formação, o movimento não consegue engrenar, apresenta relação fragilizada entre os gestores públicos, as entidades de apoio e os próprios empreendimentos, que deveriam ser os principais beneficiários.

Percebe-se que, muitas vezes, os atores das diferentes esferas tripartite apresentam-se vestidos de pré-conceito, derivados das relações culturais, sejam locais ou institucionais, que estão enraizados. Isso não permite a socialização de informações e amadurecimento de um novo diálogo. Desta forma, o movimento se isola. Já o Estado venda-se frente à execução das ações, pois precisa do processo de fomento de base, seja pela entidade de apoio ou pelas políticas municipais locais, que fornecerão ferramentas de acesso da demanda, para propor políticas de inclusão social produtivas.

Os empreendimentos por sua vez, estabelecem o que se pré determinou a "auto gestão" e acaba, em muitas situações, fechando as portas àquele que consegue agarrar-se em alguma forma de apoio, e tem um processo mais desenvolvido. Este consegue continuar buscando forças nas experiências acumuladas, extraídas das bases de formação, ou pelo aprimoramento técnico dos gestão executada.

Percebe-se que, no município, há uma necessidade de organização dos serviços prestados aos grupos de produção da economia solidária local, que têm o público do Plano Brasil Sem Miséria (PBSM), tendo em vista a projeção para o desenvolvimento territorial, pois foram constatadas as potencialidades dos empreendedores, porém necessita-se de condições técnicas e operacionais, para que os empreendimentos sejam fortalecidos e novos grupos de trabalho sejam criados, desenvolvendo ferramentas de agregação de renda, que possibilitarão as pessoas saírem da situação de extrema pobreza.

Os programas e projetos de Economia solidária fazem menção ao público vulnerável na maioria das vezes, por se tratar de geração de trabalho e renda, porém 


\section{International Jaurnal of Envirnnmental}

\section{Resilience Research and Sciente (IJERRS)}

Revista Internacional Resiliência Ambiental Pesquisa e Ciência Saciedade 5.0 Resiliência Ambiental

o movimento transmite um olhar mais aprimorado, não submetendo-se apenas a esse recorte de público. Por esse motivo percebe-se um desencontro no atendimento, quanto à responsabilidade dos gestores. Quando relatamos o processo de inclusão produtiva, nos remetemos a uma leitura que a corresponsabilidade deveria ser da Política de Assistência Social, porém o atendimento se restringe, pois esta política poderá apenas pactuar atendimento ao recorte de público pré-estabelecido.

Para efetivação da economia solidária, faz-se necessário despir-se da visão do subemprego, ou da complementação de renda. Devemos analisar a conjuntura do processo, pois esta vai além de uma proposta de geração de trabalho e renda, mas sim de uma ótica de uma "nova economia", um jeito diferente de produzir, comercializar e consumir. Estamos falando aqui de uma alternativa que vão ao encontro à valorização do ser humano, do bem-estar social, culminado no resgate das práticas antigas de cultivo para a reestruturação do equilíbrio ambiental e humano.

\section{REFERÊNCIAS}

ADAMS, T. Educação e economia solidária: mediações pedagógicas do trabalho associado. Aparecida, SP: Idéias \& Letras, 2010.

ANTUNES, R. Adeus ao trabalho? São Paulo: Cortez, 1995.

ANTUNES, R. O caracol e sua concha. São Paulo: Boitempo, 2005.

ANTUNES, R. Os sentidos do trabalho. São Paulo: Boitempo, 1999.

ANTUNES, Ricardo. Adeus ao trabalho? Ensaio sobre as metamorfoses e a centralidade do mundo do trabalho. 5. ed. São Paulo: Cortez, Campinas: Editora da Universidade Estadual de Campinas, 1998, $155 \mathrm{p}$.

BARRETO, J. dos S. O processo de organização dos catadores de materiais recicláveis de Cascavel - PR. Trabalho de Conclusão de Curso (Bacharel em Serviço Social) Faculdade UNIPAN. Cascavel, 2009.

CABRAL, J. F. P. Capital, Trabalho e Alienação, segundo Karl Marx. Disponível em: $<$ http://www.brasilescola.com/filosofia/capital-trabalho-alienacao-segundo-karl-marx.htm > Acesso em: 23 maio 2016.

Cartilha dos fundos solidários da Região Sul: histórico, organização e gestão / Centro de Assessoria Multiprofissional. - Porto Alegre: CAMP, 2015.

CURY, C. R. J. Ideologia e educação brasileira: católicos e liberais. São Paulo: Cortez, 1978. 


\section{International Journal of Environmental}

\section{Resilience Research and Sciente (IJERRS)}

Revista Internacional Resiliência Ambiental Pesquisa e Ciência Saciedade 5.0 Resiliência Ambiental

DEMO, P. Pesquisa: princípio científico e educativo. São Paulo: Cortez, 2000.

FALEIROS, V. de P. Serviço Social: questões presentes para o futuro. Serviço Social \& Sociedade, n. 50, Ano XVII, São Paulo: Cortez, abril 1996. p.09-39.

FREIRE, P. Pedagogia do oprimido. 45. ed. Rio de Janeiro: Paz e Terra, 2005.

MARX, K. O Capital: crítica da economia política. São Paulo: Nova Cultural, 1985.

MÉSZÁROS, I. Para além do capital. São Paulo: Boitempo Editora, 2002.

MINAYO, M. C. Pesquisa social: teoria, método e criatividade. 23를 ed. Petrópolis: Editora Vozes, 2004.

RAZETO, L. Economia de Solidariedade e Organização Popular. In: GADOTTI, M; GUTIERREZ, F (orgs.). Educação Comunitária e Economia Popular. 2.ed. São Paulo: Cortez, 1993.

Relatório de Programas e Ações MDS. Disponível em:

http://aplicacoes.mds.gov.br/sagi/RIv3/geral/relatorio.php\#Informações Sociodemográficas <acessado em 10 de maio de 2019>

SANTIAGO, E. G. Os Fundos Rotativos Solidários: novas utopias socialistas para o mundo do trabalho em transformação? Maranhão (Jornada Internacional de Políticas Públicas), agosto de 2011.

RIBEIRO, W. C. Em Busca da Qualidade de Vida. In: PINSKY, J. et al. História da cidadania. São Paulo: Contexto, 2003, (p.399-417).

SILVA, Andréia Vieira da. Economia solidária: uma estratégia política de desenvolvimento. João Pessoa, 2010.

SINGER, P.; SOUZA, A. R. de (Orgs). A economia solidária no Brasil: a autogestão como resposta ao desemprego. São Paulo: Contexto, 2000. p.28.

TAKAZAWA. A. Artesãos da região participam de projeto Brasil Local. Em:

$<\mathrm{http}: / /$ www.assisnoticias.com.br/site/?p=ver_noticia\&cod_noticia=3533\&cod_assunto=9\&origem =3> acessado em: 07 de maio de 2019.

TELLES, V. da S. Direitos sociais: afinal do que se trata? Belo Horizonte: Ed. UFMG, 2001.

Termo de Referência para Implantação dos Centros de Formação em Economia Solidária CFES1 - SENAES. Disponível em:

<http://portal.mte.gov.br/data/files/FF8080812B35FA90012B4BF2FAFE7B5D/prog_formacao_termo_ anex01.pdf > acessado em 28 de maio 2019

VIEIRA, E. Democracia e política social. São Paulo: Cortez, 1992.

YAZBEK, M. C. As classes subalternas como expressão de um lugar social: a exclusão integrativa.

Classes subalternas e assistência social. São Paulo: Cortez, 2006 p. 61- 81. 